\title{
New Management Algorithms for Smart Electricity Network: Designing and Working Principles
}

\author{
Ando Ny Aina Randriantsoa, Damien Fakra, Manitra Pierrot Ranjaranimaro, \\ Mohamed Nasroudine Mohamed Rachadi, and Jean Claude Gatina \\ Higher Institute of Technology of Antananarivo (I.S.T), Ministry of Higher Education \\ and Scientific research, Iadiambola Ampasampito, Po Box 8122, Antananarivo 101, \\ Madagascar \\ PIMENT Laboratory - University of La Réunion, 117 rue du General Ailleret - 97430 \\ Le Tampon - La Réunion, France \\ ando.randriantsoa.istt@gmail.com, alihamada.fakra@univ-reunion.fr, \\ pierrot.isttana@gmail.com,m.nasroudine@gmail.com, \\ jean-claude.gatina@univ-reunion.fr \\ https://piment.univ-reunion.fr/
}

\begin{abstract}
The energy needs considerably increase with the economic development of a country. The promotion of renewable energy sources was enhanced because of global awareness of fossil fuel depletion and climate changes induced by their use. The renewable energy sources are, however, intermittent in nature. Alternative solutions such as the integration of renewable energy systems into the conventional electric grids have been recommended. The integration approach uses photovoltaic, wind, and other renewable energy sources to supply sustainable energy to the built spaces during peak loads or electric back-up. In this article, we proposed a new approach to manage the energy flow in a smart grid. Two algorithms were developed to manage the integration of renewable sources combined into a storage system into a conventional power grid. The first algorithm aims to smooth the consumption peak and reduce the extraction from the conventional grid while the second aims to maximize the use of renewable energy depending on the energy demand. Reliability tests of the algorithm behavior have been conducted in comparison to the HOMER software and the results show a maximum relative error of $4.78 \%$ on the management of grid extraction. These algorithms are based on scenarios and operational parameters to optimize the integration of renewable energy in the current electricity network. Their application will reduce the negative impact of fossil energy and enhance the energy transition.
\end{abstract}

Keywords: Algorithm, Electricity, Renewable energy, Management, Smart Grid, Simulation 


\section{Introduction}

Nowadays, most activities depend on energy. For instance: transport, industry, housing, agriculture, air conditioning, health, etc. However, global energy production is dominated by fossil energy sources [1]. The exhaustible nature of this energy [2], pollution issues and the growth of global energy demands are the main factors that prompted us to adopt the strategy of sustainable development: which meets the needs of the present generation without compromising future generations. Consequently, this challenge inspired us to search for concrete solutions for energy production and management. On the other hand, the varying geographical distribution of energy resources generates geopolitical tensions and holds down the economic growth of countries which do not have enough resources [3]. The economic growth of a country depends on the growth of its energy production, consumption and management [4]. Thus, we are using renewable energy sources to address the problems of depletion and pollution of fossil energy sources. These renewable energy sources may be produced by solar radiation or wind energy, infinite energy sources [5]. Nevertheless, the renewable energy sources encounter the problem of intermittency and its dependency to external factor such as weather. For that reason, we need a storage system to contain the energy during its production phase and reuse this stored energy when needed [6]. In order to mesure-up to the energy needs, we use an energy mix system that consists of coupling several energy sources, with at least one renewable energy source. This energy mix has to be managed to optimize its use and the current electrical network becomes a smart grid. According to the European technology platform: "A smart grid is an electricity network that can intelligently integrate the actions of all users connected to it - generators, consumers and those that do both - in order to efficiently deliver sustainable, economic and secure electricity supplies" [7]. Our work deals with the development of management algorithms for that smart grid applied to a built space environment. The distribution of electrical energy flow among connected buildings will be the main objective of this study; to smooth the energy extracting energy peaks on the electricity grid and to maximize the use of renewable energy sources by combining a consumption system, a renewable energy production system and a storage system. Two management algorithms are proposed for that purpose. We will commence by presenting the different systems involved and the management strategies adopted for our study, followed by the flow charts of these algorithms. Then, we will illustrate the results of a comparative study between the new algorithms developed in this work and the HOMER tool which is the reference. Finally, the conclusion and perspectives of this work will be presented.

\section{Designing Method of the New Algorithms}

The proposed tool can manage the electric energy flow of several buildings. The buildings, presumably, have their own renewable energy production system 
(solar or wind energy) associated to a storage unit. They are also connected to an electricity network. This study will then deal with four energy systems to manage the electric energy flows (see Figure 1).

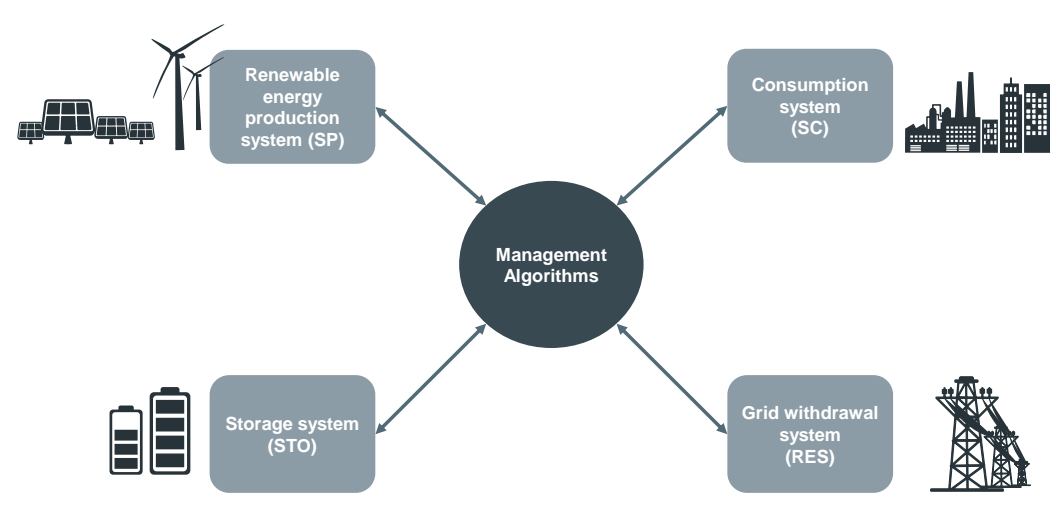

Fig. 1. The energy systems

- SP: Renewable energy production system, which is is represented by the renewable energy (in $\mathrm{kWh}$ ) generated by each building. This renewable energy can be extracted from the sun or the wind;

- SC: Consumption system, which is represented by the energy consumed by each building (in $\mathrm{kWh}$ ). It may include lightning, electrical appliances, heating, ventilation and air-conditioning (HVAC). A load profile is then attributed to each type of building through these needs;

- STO: Storage system, which is represented by the available stored energy (in $\mathrm{kWh}$ ) for each building. This storage system is a major part of a smart grid because it is used to store energy when the energy production is high and smooth the grid extraction during consumption peaks.

- RES: Grid withdrawal system, which is represented by the energy extracted from the current electrical grid (in kWh) by each building. Each country has its specific energy sources to feed that electrical grid, so that our work will consider the extracted energy without taking in consideration the source of that energy.

The proposed algorithms interact with these four systems every hour to manage the distribution of the electric energy flow. The designing method is built under an algorithmic logic made up of possible scenario cases of an energy-mix system. Every hour, the algorithm takes in consideration the renewable energy production as well as the energy demand and then takes a decision on where the 
energy will be extracted from. The algorithm alerts if there is an excess amount of energy resulting from the energy mix. In our study, the energy data is modelled in a matrix format. Thus, the calculation process has been developed in a MATLAB environment which is widely used for matrix calculation. Thus, the energy data is described by $m \times n$ matrix:

- m: rows which represent the time step (an hour);

- n: columns which represent the energy data for each connected building.

The system will be presented in the following paragraphs.

\subsection{The Consumption-Smoothing Algorithm}

The first algorithm proposed in this work has been designed to minimize consumption peaks and to smooth the energy consumption curve. When the consumption is close to a defined limit, energy is extracted from the storage system to avoid excessive extraction from the grid. Priority is given to storage system charging and this strategy saves the energy cost from the grid extraction.

The control system takes in consideration the following operating parameters:

- LH: upper limit of storage capacity (in $\mathrm{kWh}$ );

- LB: lower limit of the storage capacity (in $\mathrm{kWh}$ );

- LR: grid withdrawal limit (in $\mathrm{kWh}$ );

- $\mathrm{STO}_{i-1}$ : storage situation for the previous time step (in $\mathrm{kWh}$ ).

The management of the electric energy flow depends on the state of each one of the four systems and the values of the operating parameters. Then, at each hour of the day, the tool evaluates the power available at the renewable source, the power required by the load, the power that can be withdrawn from the grid and the power that can be supplied by the storage system. Depending on the values of these powers and the operating parameters of the storage systems and the grid, the tool decides how much energy to draw from the grid and to supply or take from the storage system. The algorithm detects if there is an excess energy production (EXC). The flow chart of the first algorithm is represented in Figure 2 and 3.

According to the first algorithm, there are two main cases which determine the management of the energy flow: the first main case is when the energy demand is less than or equal to the grid withdrawal limit. Consequently, if there is no renewable energy production, the energy will be completely drawn from the grid. On the other hand, if there is renewable energy production and the storage unit has the capacity to receive the entire renewable energy production: first, the storage system will charged, without exceeding the higher limit of storage, by allocating all of the renewable energy production to charge it. The second main case is when energy demand is higher than the grid withdrawal limit. If there is no renewable energy production but the energy from the storage system is available, the excess consumption will be covered by the storage system. If the energy from the storage system is not enough, the rest will be drawn beyond the grid 


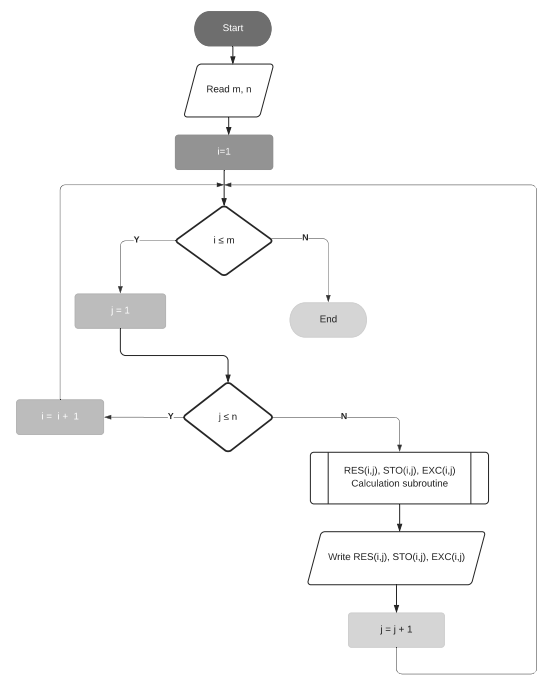

Fig. 2. The Consumption-Smoothing Algorithm

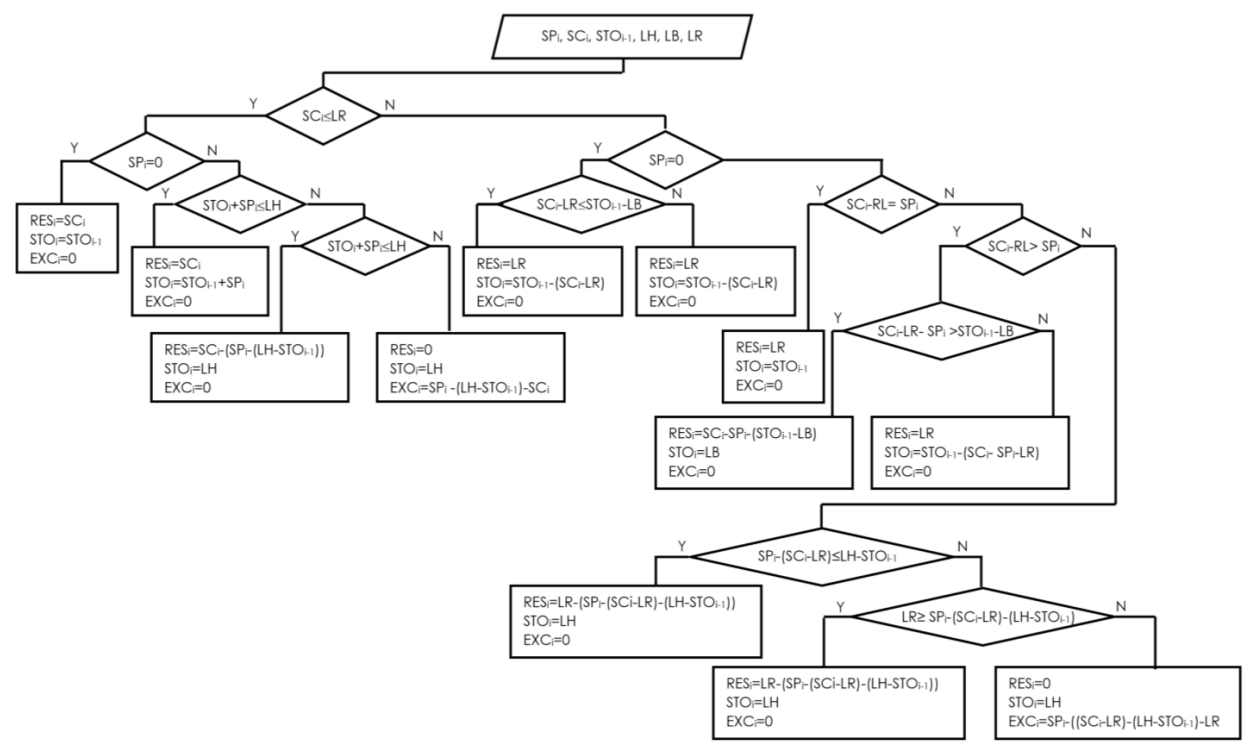

Fig. 3. The Consumption-Smoothing Calculation Subroutine 
extraction limit from the grid system. In the case of sufficient renawable energy production to support the excess consumption, a part of the energy demand will be ensured by the production of renewable energy. If there is no renewable energy production and the storage system is at the lower capacity limit, all the energy demand will be met by the grid.

\subsection{The Renewable-Energy Algorithm}

The second algorithm proposed in this work has been designed to control energy flow and maximize the use of renewable energy source. For this purpose, the energy demand is met by renewable energy sources when they are available. Therefore the storage system is recharged only when the energy demand is satisfied. The control system of the second algorithm takes the following operating parameters in consideration:

- LH: upper limit of storage capacity (in $\mathrm{kWh}$ );

- LB: lower limit of the storage capacity (in $\mathrm{kWh}$ );

- LR: grid withdrawal limit (in $\mathrm{kWh}$ );

- $\mathrm{STO}_{i-1}$ : storage situation for the previous time step (in $\mathrm{kWh}$ );

- rend_r: electrical grid efficiency (-);

- rend_bat: storage battery efficiency (-);

- rend_ond: converter efficiency (-);

- ond_out_max: maximum output power of the converter (in $\mathrm{kW}$ );

- ond_in_max: maximum input power of the converter (in $\mathrm{kW}$ ).

The second algorithm also deals with the production system and the consumption system, similar to the first algorithm. Besides, it measures the battery's charging power and discharging power to decide how the energy should be extracted from the storage system and verify if there is any excess energy production (EXC1 corresponds to the DC excess energy while EXC2 corresponds to the AC excess energy). The algorithm behavior also depends on the operational parameters just like the first algorithm. Although the additionnal parameters have been included: the electrical grid performance, the storage battery capacity, the effectiveness of the converter (maximum output power and maximum input power). Figures 4, 5, 6 and 7 respectively demonstrate the main flow chart of the second algorithm and the subroutine calculation. These flow charts specify how the proposed algorithm displays the energy flow according to each scenario.

For the second algorithm, three main cases have been identified to regulate the electric energy flows: if there is no renewable energy production, the algorithm checks if the energy consumption is less than the grid withdrawal limit. Thus, the electricity network is adequate for the energy demand. If there is renewable energy production, and the energy produced is more than the demanded energy, the algorithm will check if the operating parameters can totaly extract from this renewable energy source. Finally, if there is renewable energy produced, but the energy demand is higher, the algorithm will prioritize the use of this renewable energy and thereafter extract from the electric grid. In a nutshell, 


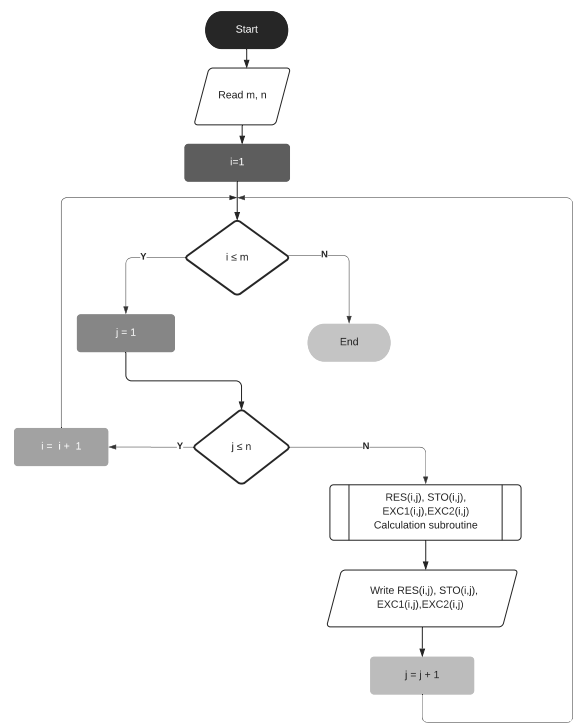

Fig. 4. The Renewable-energy Algorithm

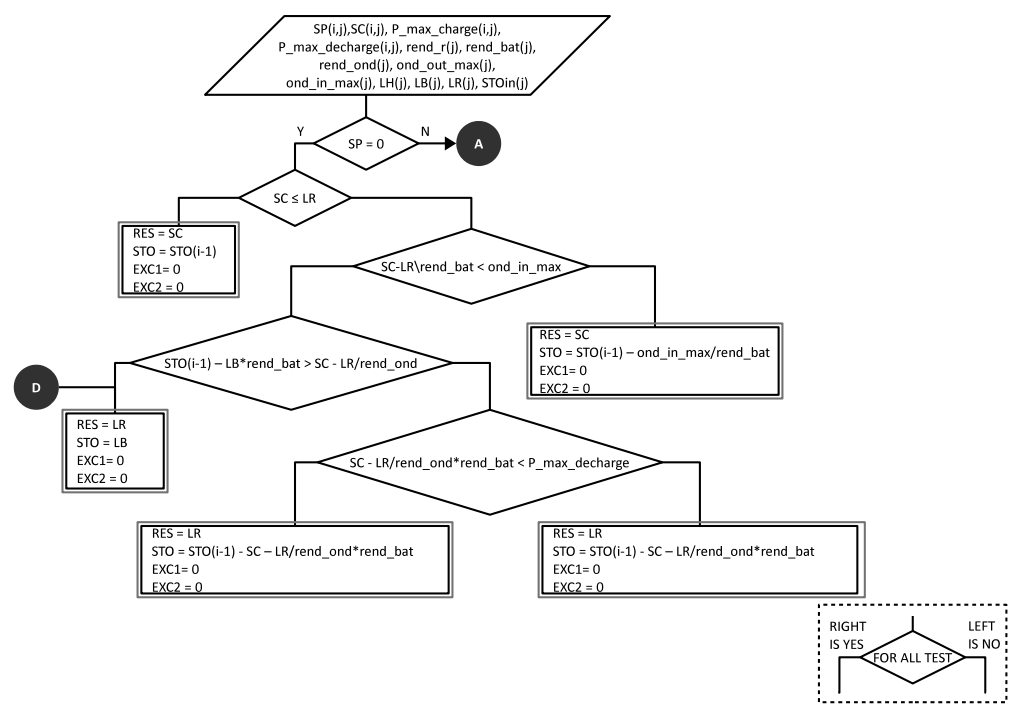

Fig. 5. The Renewable-energy Calculation Subroutine - Part 1 


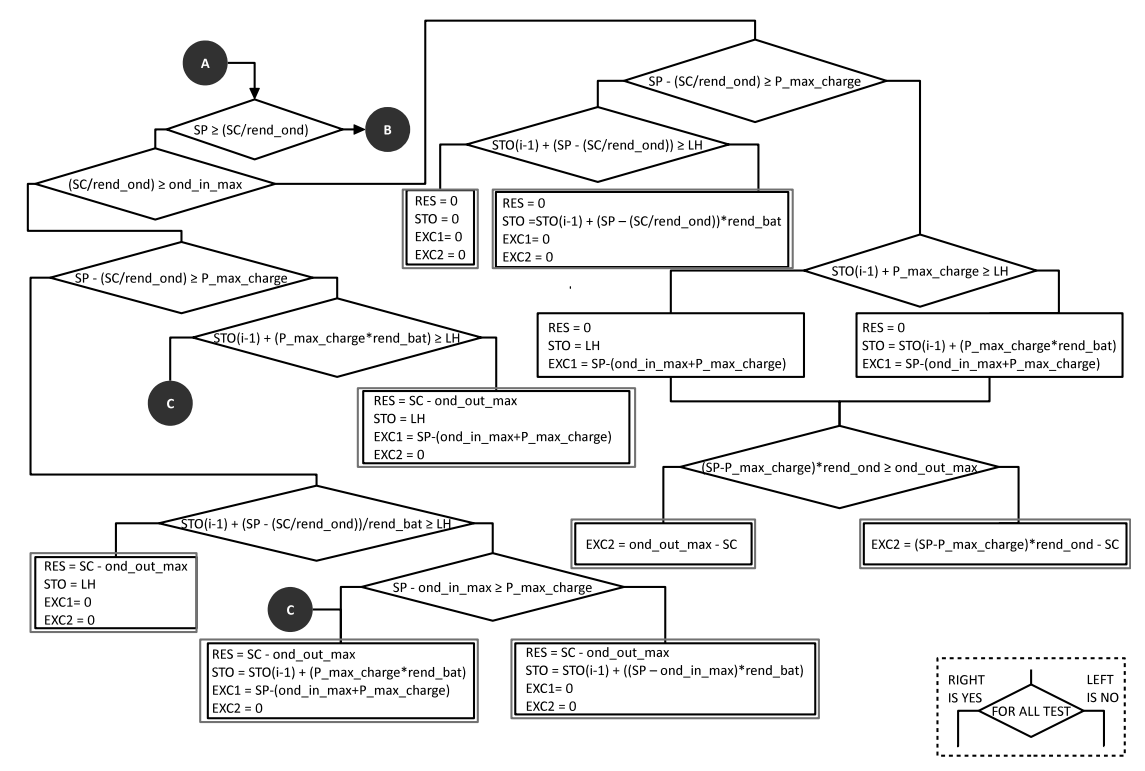

Fig. 6. The Renewable-energy Calculation Subroutine - Part 2

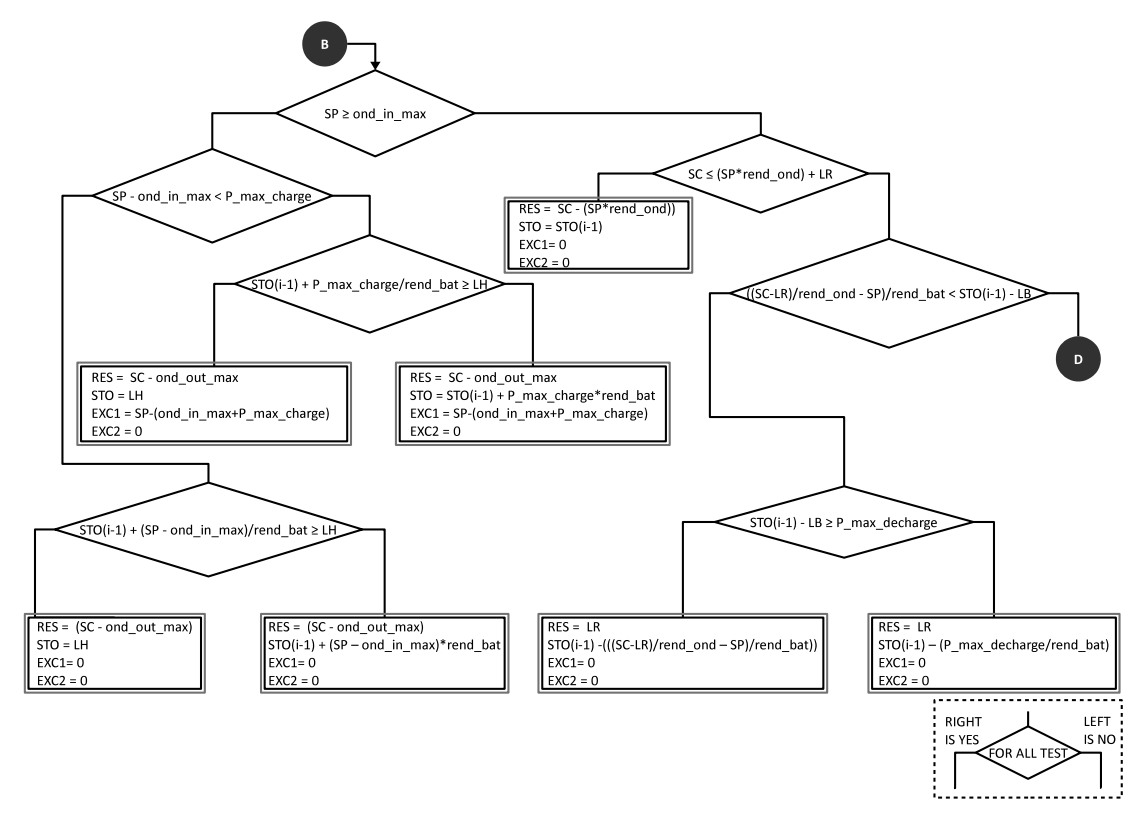

Fig. 7. The Renewable-energy Calculation Subroutine - Part 3 
the second management algorithm initially extracts from the renewable energy source, then from the electric grid and eventually from the storage system. The storage system will only be charged if the energy demand is met.

\section{Simulation Results of the Algorithms}

Two new algorithms were designed for the management of smart grid. They have been applied to similar data to evaluate their behavior. The following paragraphs will describe how the simulation have been conducted.

\subsection{Hypothesis of the Simulation}

A commercial building related to its load profile has been chosen for the simulation. The production system (SP) used for the simulation consists of solar energy production through photovoltaic panels while the storage system consists of batteries. The data related to the production system have been provided from the NASA annual database in Colorado State of the United States from 1st January at 00:00 to 31st December 2007 at 23:00 which correspond to 8760 hours of simulation.

The parameters used for the simulation are listed as following: the upper limit of storage capacity (HL) is $379.30 \mathrm{kWh}$; the lower limit of the storage capacity (LB) is $151.72 \mathrm{kWh}$; the grid withdrawal limit (LR) is $255 \mathrm{kWh}$; the electrical grid efficiency is 0.8 ; the storage battery efficiency 0.89 ; the converter efficiency is about 0.95 ; the maximum power output of the converter is $137.72 \mathrm{~kW}$ and the maximum input power of the converter is $144.97 \mathrm{~kW}$.

\subsection{Behavior of the Algorithms}

The algorithms have been included in a MATLAB environmnet for the matrix calculation process. This process represent the behavior of the two algorithms. Thus, the behavior of the two algorithms can be displayed as curves to be visualized. Figures 8 and 9 respectively explain the behavior of the first and the second algorithms. The time range vary from 4870 hours (2007-07-22 at 21:00) to 4950 hours (2007-07-26 at 05:00).

The simulation shows that the management of the storage unit is distinctive for the two algorithms. The first algorithm prior to charging storage batteries while the second algorithm prior to the use of renewable energy to fulfill the energy consumption. For the Renewable-Energy Algorithm, the storage batteries are used to response the energy consumption when that consumption exceeds the grid withdrawal limit. We also remark that the energy extraction from the grid is slightly low for the Consumption-Smoothing Algorithm compared to the Renewable-Energy Algorithm without exceeding the grid withdrawal limit. 


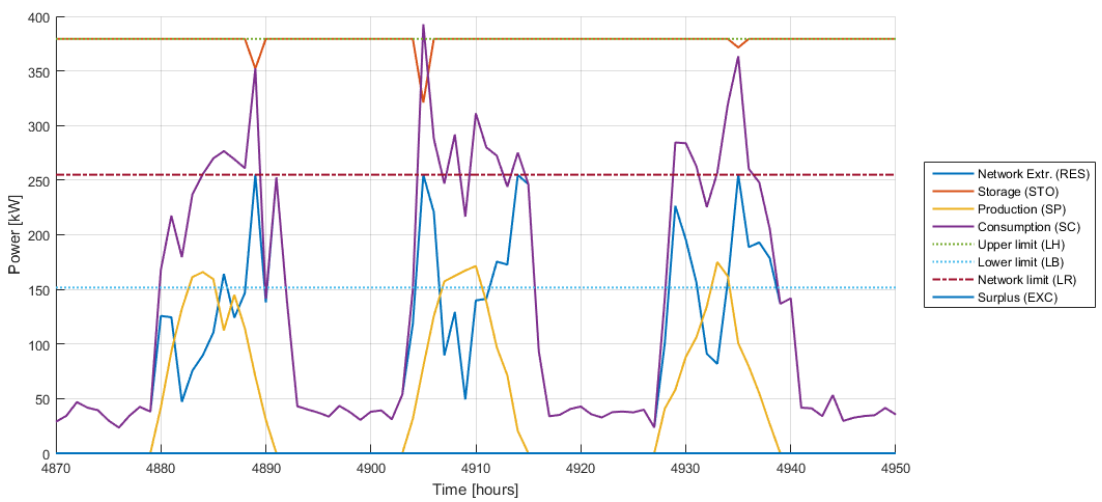

Fig. 8. The Consumption-Smoothing Algorithm behavior

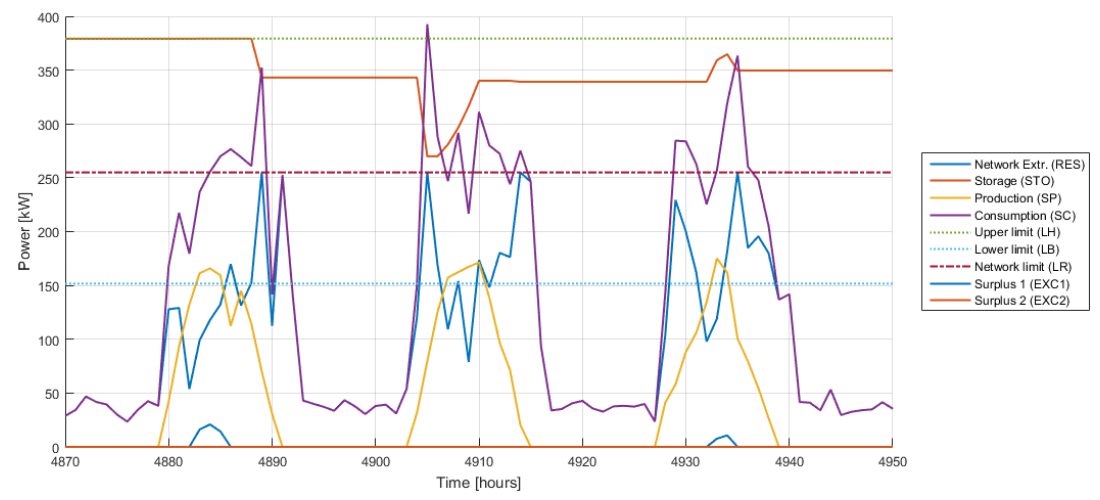

Fig. 9. The Renewable-Energy Algorithm behavior 


\subsection{Reliability Tests of the Algorithms}

The algorithms proposed in this work have been validated by comparison with another tool (HOMER software) under the same parameters to confirm their reliability. HOMER is commonly used in research and validated by the researchers' community. The HOMER software has been developed at the National Renewable Energy Laboratory (NREL, USA) [8] and it is widely used by researchers to conduct simulations on new configurations of renewable energy systems [9], [10], [12], [11].

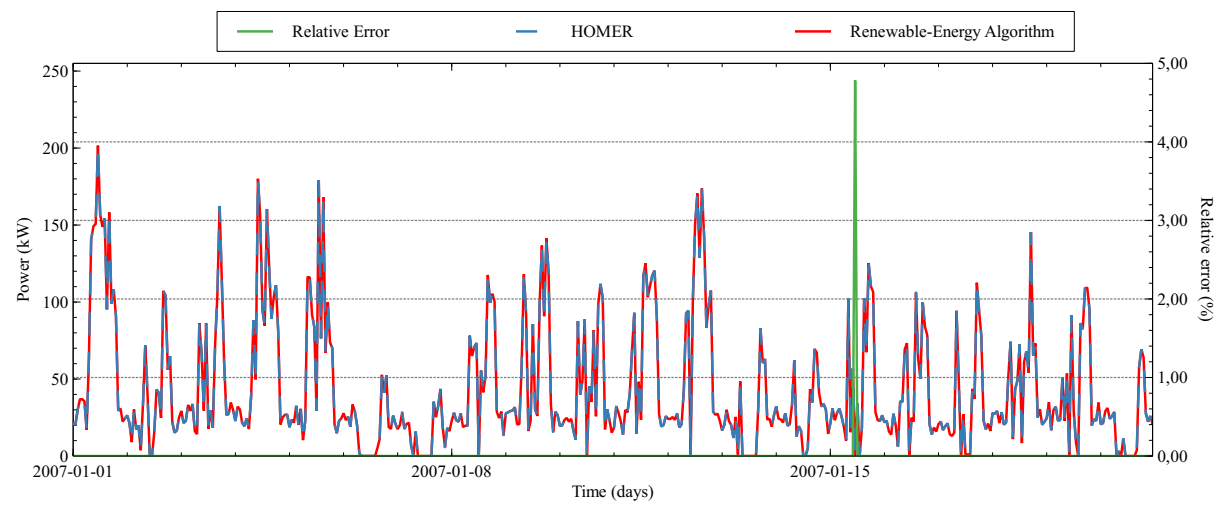

Fig. 10. Grid Extraction of the Proposed Algorithm Compared to HOMER

The comparison results (see Figure 10)show that the Renewable-Energy Algorithm meets the comparison with HOMER. The maximum relative error observed relates to the grid extraction system. The difference in power is about $45.2 \mathrm{~W}$, then, the maximum relative error value is $4.78 \%$. The grid withdrawal limit for the commercial building used in this simulation is about $255 \mathrm{kWh}$ and the difference in power between HOMER and the Renewable-Energy Algorithm is about $5.34 \mathrm{~W}$. Consequently, the power difference compared to the grid withdrawal limit is negligible $\left(1.77 \times 10^{-2 \%}\right)$.

\section{Conclusion}

In order to overcome the current problems of energy and improve the productivity of systems integrating renewable energy sources, two new algorithms for managing the flow of electrical energy are suggested. For each time step, the proposed algorithms either decide the amount of energy to be withdrawn from the grid and the storage system or used to supply the load and the storage unit. The decisions made by these algorithms are determined from data related to the production system and the energy demand from the consumption system. The first algorithm has been developed to reduce consumption peak by optimally 
managing the extraction of energy from the conventional electricity grid. The second algorithm aims to maximize the use of renewable energy to meet the energy demand. Thus, the choice of the algorithm to be used depends on the final objective of the users. Finally, reliability tests of the algorithm have been conducted by comparing the results obtained in the simulation of a commercial building with those given by the HOMER software. The maximum relative error obtained between the two tools is $4.78 \%$ on the power withdrawn from the grid. These values demonstrate the reliability of the proposed algorithm. In conclusion, the two algorithms have one common point: the efficient management of an energy mix integrating renewable energy. However, the objectives of each algorithm are different: the first one is based on the financial economy of the network and the second in the availability of renewable energy in this electricity network.

\section{Acknowledgments.}

This work has been developed with the collaboration of the Higher Institute of Technology of Antananarivo (I.S.T), Ministry of Higher Education and Scientic Research, Iadiambola Ampasampito, Po Box 8122, Antananarivo 101, Madagascar and the PIMENT Laboratory, University of la Réunion, 117 rue du General Ailleret - 97430 Le Tampon, France and has been funded by the ERASMUS+ project and "La Région Réunion".

\section{The References Section}

\section{References}

1. Martins, F., Felgueiras, C., Smitková M.: Fossil fuel energy consumption in European countries. Energy Procedia. 153, 107-111 (2018)

2. Fantazzini, D., Höök, M., Angelantoni A.: Global oil risks in the early 21st century. Energy Policy. 39, 7865-7873 (2011)

3. Krane, J., Medlock, K. B.: Geopolitical dimensions of US oil security. Energy Policy. 114 , pp. 558--565 (2018)

4. Kibria, A., Akhundjanov, S.B., Oladi R.: Fossil fuel share in the energy mix and economic growth. International Review of Economics and Finance. vol. 59. pp. 253-$264(2019)$

5. Sørensen, B.: 2 - Origin of renewable energy flows. Renewable Energy (Fifth Edition). Éd. Boston: Academic Press, p. 39-218 (2017)

6. Trainer T.: Some problems in storing renewable energy. Energy Policy. 110, p. 386393 (2017)

7. Dileep G.: A survey on smart grid technologies and applications. Renewable Energy. 146, p. 2589-2625 (2020)

8. HOMER - Hybrid Renewable and Distributed Generation System Design Software, https://www.homerenergy.com/ (2020-03-19)

9. Prasetyaningsari, I., Setiawan, A., Setiawan, A.A.: Design Optimization of Solar Powered Aeration System for Fish Pond in Sleman Regency, Yogyakarta by HOMER Software. Energy Procedia. 32, 90-98 (2013) 
10. Kim, I., James, J-A., Crittenden, J.: The case study of combined cooling heat and power and photovoltaic system for building customers using HOMER software. Electric Power System Research. Vol. 143, pp 490-502 (2017)

11. Zahboune, H., Zouggar, S., Krajacic, G., Varbanov, P.S., Elhafyani, M., Ziani, E.: Optimal hybrid renewable energy design in the autonomous system using modified electric system cascade analysis and Homer software. Energy Conversion and Management. Vol. 126, pp. 909-922 (2016)

12. Shahzad, M. K., Zahid, A., Rashid, T.U., Rehan, M.A., Ali M., Ahmad, M.: Techno-economic feasibility analysis of a solar-biomass off-grid system for the electrification of remote rural areas in Pakistan using HOMER software. Renewable Energy. pp. 264-273 (2017) 